\title{
View-specific effects of depth rotation and foreshortening on the initial recognition and priming of familiar objects
}

\author{
REBECCA LAWSON and GLYN W. HUMPHREYS \\ University of Liverpool, Liverpool, England \\ and Cognitive Science Research Centre, University of Birmingham, Birmingham, England
}

\begin{abstract}
In a series of three experiments, we examined, first, the effects of viewpoint in depth on the efficiency of initial picture naming and, second, the effects of priming on subsequent naming. On initial presentation, foreshortened views were harder to name than were more typical (nonforeshortened) views. In addition, priming increased as a function of the similarity of the prime and target. Indeed, if a foreshortened view of an object had already been named, the subjects named a subsequent foreshortened view of that object as fast as or faster than they named a subsequent, more typical view. These results provide evidence against theories that predict full view-invariant object recognition and view-invariant priming of object recognition. Instead, the results support theories that suggest that object recognition is mediated by stored representations that are both view- and object-specific.
\end{abstract}

Any theory of human visual object recognition must be able to account for our remarkable ability to achieve object constancy - that is, our ability to recognize objects despite transformations-such as scaling, position changes, and plane and depth rotation-that drastically alter the image subtended by an object. Arguably, our ability to achieve object constancy over depth rotation provides the most stringent test of the visual recognition system, since two views of an object separated by a rotation in depth will frequently differ in occluding contour and the visibility of features and parts, as well as in the spatial relations between features and parts. Scaling, position changes, and plane rotations do not result in such extensive image alterations, and artificial intelligence solutions to the problem of achieving object constancy over these last transformations are relatively straightforward.

Interestingly, there has been less research into the effects of depth rotation on object recognition than into the effects of plane rotation, scale, and position transformations (see, e.g., Biederman \& Cooper, 1991a, 1991b, 1992; Jolicoeur, 1985). However, recent studies have examined the naming of both familiar depth-rotated objects (see, e.g., Humphrey \& Jolicoeur, 1988, 1993; Palmer, Rosch, $\&$ Chase, 1981) and novel objects (see, e.g., Tarr, Hayward, Gauthier, \& Williams, 1994), the priming of identification of familiar objects (see, e.g., Bartram, 1974; Bie-

This work was supported by grants from the Human Frontier Science Program (Grant LT-558/94) and from the Science and Engineering Research Council of Great Britain (Grant 9031212X) to the first author and by a grant from the Economic and Social Research Council of Great Britain (Grant R000234279) to the second author. Reprint requests should be sent to R. Lawson, Department of Psychology, University of Liverpool, Eleanor Rathbone Building, Bedford Street South, Liverpool, L69 7ZA, U.K. (e-mail; rlawson@liverpool.ac.uk). derman \& Gerhardstein, 1993; Srinivas 1993, 1995), the matching of familiar objects (see, e.g., R. Ellis, Allport, Humphreys, \& Collis, 1989; Humphrey \& Lupker, 1993; Lawson \& Humphreys, 1996), the matching of novel, depth-rotated objects (see, e.g., Biederman \& Gerhardstein, 1993; Farah, Rochlin, \& Klein, 1994; Tarr et al., 1994), and recognition memory for novel objects (see, e.g., Edelman \& Bülthoff, 1992; Humphrey \& Khan, 1992; Rock \& Di Vita, 1987; Rock, Di Vita, \& Barbeito, 1981). Unfortunately, these diverse studies have not provided a clear and consistent picture of the effects of depth rotation on the efficiency of object recognition. Indeed, results range from those of studies that suggest that recognition is largely insensitive to view in depth (see, e.g., Biederman \& Gerhardstein, 1993, Experiment 1, in a priming study of the naming of line drawings of familiar objects) to those of studies in which performance was found to be highly dependent on view in depth (see, e.g., Edelman \& Bülthoff, 1992).

Biederman and Gerhardstein (1993) argued that many, if not all, of the studies that suggest that recognition is highly view dependent used tasks and experimental stimuli that do not accurately reflect the ecological recognition of objects at a basic level. There has been criticism of these claims (see, e.g., Tarr \& Bülthoff, 1995; but see also Biederman \& Gerhardstein, 1995). Here we provide a further test of these claims, by employing tasks (naming and the priming of picture naming) and stimuli (line drawings of familiar objects drawn from different basic level categories) that are similar to those employed in the studies of Biederman and Gerhardstein (1993, 1995). In our studies, we investigated whether the recognition of familiar objects was view sensitive even under these conditions and, if so, how sensitive object recognition was to variation in the view in depth of an object. 
In this paper, two different effects of viewpoint on picture identification were examined. First, we investigated the recognition and naming of stimuli that had not been seen before (although representations of the object classes were assumed to be stored by subjects). The stimuli were line drawings of familiar objects, depicted from a range of different, carefully controlled views in depth. To date, there has been little research into the effects of view in depth on the initial recognition efficiency of familiar objects. A disadvantage in recognizing foreshortened views has been reported for both normal subjects (Humphrey \& Jolicoeur, 1988, 1993; Srinivas, 1993, 1995) and for neuropsychological patients (Humphreys \& Riddoch, 1984; Warrington \& Taylor, 1973, 1978). However, no attempt was made in any of these studies to investigate systematically the effects of depth rotation across a range of different views. This was, however, done in the present studies.

Second, we examined the effects of view on the priming of picture naming. View effects on priming may differ from view effects on initial object naming, and priming studies can provide more detailed information about the view sensitivity of the visual processing system than can studies of the efficiency of initial picture naming. Studies such as those reported by Humphrey and Jolicoeur (1993) and by Palmer et al. (1981) indicate that, on initial presentation, some views of an object are more canonical and easier to recognize than others. Although this result is interesting, effects of view on initial naming can be accounted for by differences in relatively early stages of visual processing that are not specific to the objects presented, with canonical views being encoded more efficiently than other views. As we outline below, using priming, we can distinguish between those view-specific effects that are due to early, general visual processes and those that are due to later, object-specific visual processes.

Consider two possible loci of view effects on object recognition. First, effects may be the result of variation in the efficiency of early, general visual processing for different, depth-rotated views, caused by variation in the ease of encoding image representations. For example, Marr (1982) suggested that a foreshortened view disadvantage may be caused by difficulties in deriving the main axis of an object from a foreshortened image. Within a bottom-up framework for vision (Marr, 1982), this problem occurs prior to, and outside of, the influence of stored representations of particular objects. Second, and in contrast, view effects may be caused by relatively late, object-specific difficulties in matching "on-line" image descriptions of certain views to view-sensitive stored object representations (e.g., because parts of the object specified in its structural description are obscured; see Biederman, 1987; Biederman \& Gerhardstein, 1993).

Thus, view-specific effects on recognition can be accounted for by both early, general visual processes and later, object-specific processes, and the relative contribution of these two processes to initial identification cannot be determined. However, the probable loci of view effects can be distinguished by studies of priming. First, suppose that view effects are wholly a result of variation in early, general visual processes, prior to the matching of the views to memory. Any priming of these early procedures may be view specific but should not be specific to the objects presented as primes. Object-specific priming may still occur in this case - for instance, because of the preactivation of object semantics and name representations-but such priming should be independent of the effects of viewpoint; good and poor views should produce equal object-specific priming of target identification.

In contrast, if view effects are the result of different views of an object activating different stored object representations, priming may be sensitive to the specific combination of the view and the object being presented. Specifically, if stored object representations are view specific, activation of a particular representation by a prime should benefit most the subsequent recognition of targets that are matched to the same view-sensitive representation. Such priming would thus be tied to the particular view of a particular object that subjects have already experienced. Greater priming would be predicted for views that are similar to or identical to previously recognized views, independent of the effects of the canonicality or "goodness" of a view (cf. Palmer et al., 1981).

The degree of specificity of any such view- and objectsensitive priming should also help to constrain hypotheses about the nature of the stored representations involved in object recognition. On some accounts, such as the recognition-by-components theory of Biederman (1987), priming should generally be independent of viewpoint, since the derived image descriptions should be relatively robust to viewpoint change. View-specific priming should emerge only under conditions in which a change in view alters the visibility of parts or of the spatial relations between parts across two views of an object (Biederman \& Gerhardstein, 1993).

Three picture naming experiments are reported in this paper, in which these issues are investigated. In Experiment 1 , we assessed the effect of view in depth on the initial naming of line drawings of familiar objects. In addition, we investigated view effects on priming. The view of the object first named (the prime) was manipulated relative to a subsequent view of the object (the target), which was named in a second block. The results suggested, first, that, on initial presentation, foreshortened views were the most difficult to name and, second, that targets were primed most effectively by primes that were similar to the target.

In Experiment 2, we investigated the effect of view in depth on the initial naming of familiar objects and focused on the effects of severe foreshortening, using a set of highly foreshortened line drawings of objects. As in Experiment 1, there was a clear disadvantage for naming the fully foreshortened view of an object when it was first presented. However, unlike Experiment 1, increasingly foreshortened views were increasingly difficult to name, resulting in a monotonic relation between the degree of 
foreshortening and the ease of object recognition. Thus, the foreshortened view disadvantage extended over a range of views rotated away from the fully foreshortened view.

In Experiment 3, we investigated the effects of view on priming, as in Experiment 1; however, in Experiment 3, we employed the same stimuli as those in Experiment 2 and focused on the effects of view in depth on the priming of extremely foreshortened views. The results of Experiment 3 fully supported those of Experiment 1, with targets being primed most effectively by views that were similar to the target, even when the prime and target differed in view by as little as a $10^{\circ}$ rotation in depth. Together, the results of the three experiments suggest that highly view- and object-specific representations are used in object recognition and priming.

\section{EXPERIMENT 1}

In Experiment 1, we investigated two related questions. First, how does depth rotation influence the initial identification of familiar objects? Second, what is the effect of view in depth on the priming of naming these stimuli? With respect to the first issue, there have been a number of studies that have reported relatively poor initial recognition of foreshortened views of familiar objects, in both the normal and the neuropsychological literature (Humphrey \& Jolicoeur, 1988, 1993; Humphreys \& Riddoch, 1984; Srinivas, 1993; Warrington \& Taylor, 1973, 1978). Of particular interest is the study by Humphrey and Jolicoeur (1993), in which subjects named line drawings of foreshortened $\left(80^{\circ}\right)$ and nonforeshortened $\left(45^{\circ}\right)$ views of common objects. The $80^{\circ}$ foreshortened views were depicted from an elevated angle and had been carefully selected so as not to occlude components, parts, or features. Despite these measures, foreshortened views were named more slowly and less accurately than were nonforeshortened views, which suggests that foreshortening per se reduces the efficiency of object recognition, even when foreshortening does not lead to the accretion and deletion of object parts.

However, as outlined in the introduction, this foreshortened view disadvantage could be due to view specificity being localized at different stages of visual processing. There could be a general problem in the initial visual encoding of foreshortened views, and/or there may be a later, object-specific problem in identifying foreshortened views that is due to the disruption of matching to stored view-specific object representations. Note that the quality of a particular view of an object (as determined, for example, by the occlusion of an important defining feature) may influence view-specific effects at either or both of these stages of visual processing.

If all view-specific effects arise early in processing, we can predict that object-specific priming will be viewinvariant. This follows if view- and object-specific effects influence separate stages of object recognition (respectively, initial general encoding processes and subsequent object-specific access to stored knowledge). In contrast, if view-specific effects are due solely to later objectspecific processes, all priming should be both view- and object-specific. In this latter case, any initial disadvantage in naming foreshortened objects (for example) should be reduced if the same objects have earlier been seen in foreshortened views, but not if (1) other objects have been seen in foreshortened views or (2) the same objects have been seen in a canonical view. This is because when both primes and targets are foreshortened, they should be matched to the same stored object representation, whereas canonical primes may be matched to a different viewspecific representation. Finally, priming effects may be a combination of early, general, and later object-specific processing. Studies of the effects of viewpoint changes on priming provide a critical test of theories of visual object recognition.

In Experiment 1, we investigated the effect of priming on object naming as a function of the view in depth of prime and target stimuli. The design of the experiment was very similar to that of Experiment 1 of Biederman and Gerhardstein (1993). The results from that experiment led the authors to conclude that the priming of visual recognition of familiar objects was relatively robust to changes in view in depth. Similar conclusions have been reached from other experiments in which the effects of visual similarity on the priming of face and object recognition were investigated (Bruce \& Valentine, 1985; Brunas, Young, \& A. W. Ellis, 1990; Brunas-Wagstaff, Young, \& A. W. Ellis, 1992; Johnston, Barry, \& Williams, 1996; Warren \& Morton, 1982; but see A. W. Ellis, Young, Flude, \& Hay, 1987); however, previous studies have not examined the range of views and stimuli used here.

In Experiment 1, subjects named the same set of familiar objects twice, once in a prime block and then around 5 min later in a target block. In the prime block, objects were presented at a range of different views. In the target block, the subjects only saw either noncanonical, foreshortened views or relatively canonical, nonforeshortened views. These two target views were selected for comparison on the basis of a rating study in which the same stimuli were used (Lawson \& Humphreys, 1996). The stimuli presented in Experiment 1 were similar to those employed by Humphrey and Jolicoeur (1993); they were line drawings of familiar objects depicted from an elevated angle that revealed the upper surface and major parts of each object. The effects of foreshortening would, therefore, not be expected to be as severe as those for objects depicted from a less elevated angle (see Experiments 2 and 3; Figure 1).

\section{Method}

Subjects. There were 84 subjects, who were paid to participate. In all of the experiments reported in this paper, the subjects were from the University of Birmingham, England, and were native speakers of English, aged between 18 and 35 years of age, with normal or corrected-to-normal vision.

Materials. A set of six views of each of 36 familiar objects was produced (see Appendix A). All the objects possessed an unambiguous main axis of elongation, and the objects were rotated about 


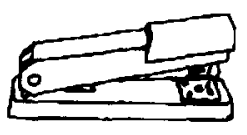

$0^{\circ}$
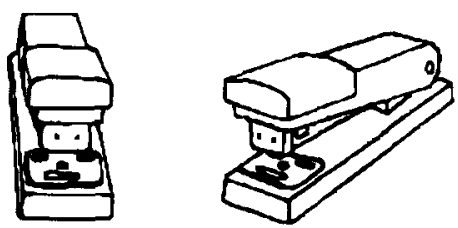

$120^{\circ}$

$90^{\circ}$
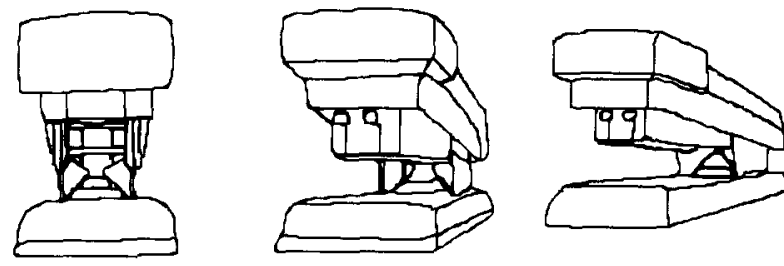

$90^{\circ}$

$80^{\circ}$ $150^{\circ}$

$70^{\circ}$

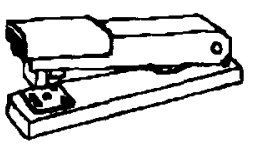

Figure 1. A comparison between the different views of the stapler presented in the two picture sets used in this paper. The upper six pictures are examples of the views presented in Experiment 1. The lower three pictures are examples of the views presented in Experiments 2 and 3.

the vertical axis running through their center point. Each view was separated by $\mathrm{a} 30^{\circ}$ horizontal rotation in depth. The angle of view was defined with respect to the line of sight of the viewer, relative to the main axis of the object. The $0^{\circ}$ view revealed the main axis perpendicular to the line of sight of the viewer. In the $90^{\circ}$ foreshortened view, the main axis of elongation pointed directly toward the viewer and revealed either the most familiar front of the object or the view with the most important feature to the front (e.g., the $90^{\circ}$ view of a kangaroo was depicted facing head on rather than tail on, and the saw was depicted with the blade closest to the viewer, and the handle furthest away). Six views of each object were produced, at $0^{\circ}, 30^{\circ}, 60^{\circ}, 90^{\circ}, 120^{\circ}$, and $150^{\circ}$ views (see Figure 1; see also Lawson \& Humphreys, 1996).

The stimuli were line drawings, produced by tracing and then scanning photographs or scale models of the objects. The photographs were taken from a slightly elevated angle of between $15^{\circ}$ and $30^{\circ}$ above the horizontal plane on which the object rested. This angle was maintained as a constant during the depth rotation of each object. An elevated angle was used in order to ensure that the effects of foreshortening the main axis of the object were not too severe and that all views were recognizable. Each picture was scaled so as to occupy a square of $6 \times 6 \mathrm{~cm}$.

Design. The subjects completed two blocks of trials-a prime and then a target block. Each subject saw one view of each of the 36 objects in each block. For the prime block, there were six different picture sets. In each prime picture set, 6 of the 36 objects were shown at each of the six different depth-rotated views $\left(0^{\circ}, 30^{\circ}, 60^{\circ}\right.$, $90^{\circ}, 120^{\circ}$ and $150^{\circ}$ ). The set of 6 objects shown at each view was rotated in a Latin Square design across the different prime picture sets, so that, over all the picture sets, each object was seen six times, once at each view. Fourteen subjects were assigned to each prime picture set. Of these 14, 7 were then presented with the foreshortened $90^{\circ}$ view target block and 7 with the canonical $150^{\circ}$ view target block, in which all 36 objects were shown in either the $90^{\circ}$ or the $150^{\circ}$ view, respectively. The order of presentation of trials within a block was random and was different for each subject.

Apparatus and Procedure. A Macintosh IIci computer running the Psychlab Version 8.5 presentation package was used to display the stimuli. The experiment lasted about $10 \mathrm{~min}$.

The procedure for each trial was as follows: A fixation cross appeared on the screen for $500 \mathrm{msec}$, followed immediately by the picture, which was displayed until the subject responded by naming the object. Responses were recorded by the computer, using a microphone and a voice-activated relay.

Before the start of the experiment, the subjects read a list of the names of the objects that would appear. This measure was intended to reduce variability in name finding (Biederman \& Cooper, 1991a; Srinivas, 1993). The subjects were then given a block of practice trials, in which objects that were different from those presented in the experimental trial were used. The subjects were encouraged to name the pictures as rapidly and as accurately as possible.

\section{Results}

Response latencies (RTs) less than 300 msec or exceeding 3,000 msec were discarded as errors. In addition, trials in which the subjects used an inappropriate name or in which the microphone was accidentally activated before the subject responded were discarded as errors. All subjects scoring over $33 \%$ errors across the 36 objects in the experiment were replaced. Errors for a given object were counted if they occurred in either the prime or the target block; so, to be included, the subjects had to name at least 25 of the 36 objects correctly in both the prime and the target block. Nine subjects were replaced in Experiment 1 by this criterion, of whom six had received the canonical view only target block.

Mean correct RTs over subjects in the prime and target blocks are shown in Figure 2; errors are given in Table 1. In this and in the following experiments, the results for both by-subjects and by-items analyses are reported, using subscripts $F_{1}$ and $F_{2}$, respectively. Separate analyses of variance (ANOVAs) were conducted on the results from the prime and the target blocks.

Prime block only analysis. For the analysis of the prime block alone, a trial was discarded only if an error occurred in the prime block (see Table 1). An ANOVA was conducted on the mean correct naming RTs. There was one within-subjects factor, prime view (the view of the picture presented in the prime block, $0^{\circ}, 30^{\circ}, 60^{\circ}$, $90^{\circ}, 120^{\circ}$, or $150^{\circ}$ ).

The main effect of prime view was significant across subjects and marginally significant across items $\left[F_{\mathrm{I}}(5,415)\right.$ $\left.=5.121, p<.001 ; F_{2}(5,175)=2.202, p<.06\right]$. For subjects only, $90^{\circ}$ views were named more slowly than were $30^{\circ}, 60^{\circ}, 120^{\circ}$, and $150^{\circ}$ views $(p<.05$; Newman-Keuls analysis). In addition, $0^{\circ}$ views were named more slowly than $60^{\circ}$ views $(p<.01)$. 
An ANOVA was also performed on the log-linear transformed error scores. The effect of prime view was significant $\left[F_{1}(5,415)=4.227, p<.001 ; F_{2}(5,175)=3.560\right.$, $p<.005]$. There were fewer errors in naming $120^{\circ}$ views than in naming $0^{\circ}, 90^{\circ}$, or $150^{\circ}$ views $(p<.05$; NewmanKeuls analysis), and $30^{\circ}$ views $(p<.05$ for subjects, not significant for items).

A second analysis of the prime block only data was conducted, including target view (the view of the picture presented in the target block, $90^{\circ}$ or $150^{\circ}$ ) as a betweensubjects factor. There was no significant effect of target view and no significant interaction of prime view $\times$ target view for RTs or for errors. This analysis was conducted as a precautionary measure, and it provided no evidence to suggest that there was a difference in the prime block between the subjects assigned to the two different target view conditions.

Target block only analysis. For the analysis of the target block, a trial was discarded if the subject made an error in naming an object in either the prime block, the target block, or both blocks (see Table 1). In the items analysis, a small number of empty cells were replaced by the mean for that condition. An ANOVA was conducted on the mean correct naming RTs. There was one within-subjects factor, prime view $\left(0^{\circ}, 30^{\circ}, 60^{\circ}, 90^{\circ}, 120^{\circ}\right.$, or $\left.150^{\circ}\right)$, and one between-subjects factor, target view $\left(90^{\circ}\right.$ or $\left.150^{\circ}\right)$.

The main effect of prime view on target block naming was not significant $\left[F_{1}(5,410)=0.362, p>.8 ; F_{2}(5,175)=\right.$
$0.396, p>.8]$, nor was the main effect of target view significant $\left[F_{1}(1,82)=1.336, p>.2 ; F_{2}(1,35)=0.049, p>\right.$ .8]. The interaction of prime view $\times$ target view was significant $\left[F_{1}(5,410)=3.809, p<.003 ; F_{2}(5,175)=\right.$ $3.517, p<.005]$.

Separate trend analyses were conducted for the $90^{\circ}$ and $150^{\circ}$ target block RTs. For the $90^{\circ}$ targets, the analysis revealed a significant quadratic component to the RT function $\left[F_{1}(1,204)=8.4217, p<.01 ; F_{2}(1,174)=\right.$ $6.9011, p<.01]$. The linear, cubic, and quartic components were not significant. For the linear component, $F_{1}(1,204)=3.6320, p>.05, F_{2}(1,174)=2.3060, p>$ .05 ; for the cubic component, $F_{1}(1,204)=0.0382, p>$ $.05, F_{2}(1,174)=0.2763, p>.05$; and for the quartic component, $F_{1}(1,204)=0.0074, p>.05, F_{2}(1,174)=$ $0.0987, p>.05$. Similarly, for the $150^{\circ}$ targets, there was a significant quadratic component to the RT function $\left[F_{1}(1,204)=4.9578, p<.05 ; F_{2}(1,174)=5.3060, p<\right.$ $.01]$. The linear, cubic, and quartic components were again not significant. For the linear component, $F_{1}(1,204)=$ $0.3742, p>.05, F_{2}(1,174)=0.1573, p>.05$; for the cubic component, $F_{1}(1,204)=0.0666, p>.05, F_{2}(1,174)=$ $0.0263, p>.05$; and for the quartic component, $F_{1}(1,204)=$ $0.6328, p>.05, F_{2}(1,174)=0.2928, p>.05$.

These reliable quadratic components were due to the mean RT's being bowed about the $90^{\circ}$ prime view for both $90^{\circ}$ and $150^{\circ}$ target views. RTs to $90^{\circ}$ targets were fastest when the primes were also $90^{\circ}$ views; in contrast,

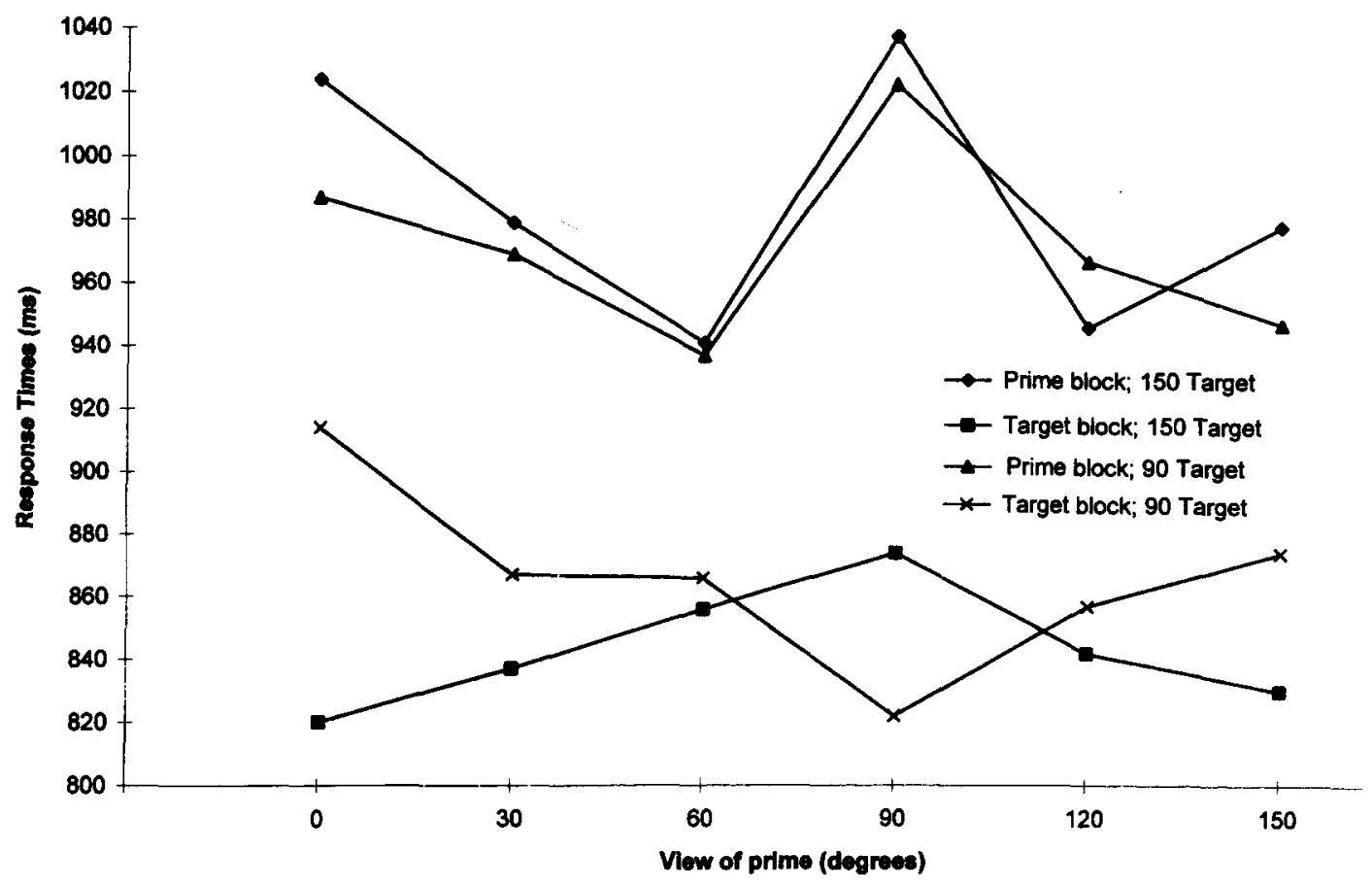

Figure 2. Mean correct response times for prime and target block trials in which the subject named the object correctly in both blocks, for $90^{\circ}$ and $150^{\circ}$ target views, as a function of prime view, in Experiment 1 . Note that the $x$-axis plots the prime view of an object presented and that the two lower lines of the figure plot responses to identical target views (either all $90^{\circ}$ or all $150^{\circ}$ target views); hence the differences between the points along the lower two lines were due solely to the experience of subjects in the previous prime block with a particular set of objects. 
Table 1

Mean Error Rates (\%) For Errors Made in the Prime Block Alone (Used in the Prime Block Analysis), Errors Made to Objects in the Prime, the Target or in Both Blocks (Used in the Target Block Analysis), and Errors Made in the Target Block, Irrespective of the Errors Made in the Prime Block, as a Function of Prime and Target View in Experiment 1

\begin{tabular}{crrrrrr}
\hline & \multicolumn{6}{c}{ Prime View } \\
\cline { 2 - 7 } Target View & $0^{\circ}$ & $30^{\circ}$ & $60^{\circ}$ & $90^{\circ}$ & $120^{\circ}$ & $150^{\circ}$ \\
\hline \multicolumn{7}{c}{ Prime Block Alone Errors } \\
$150^{\circ}$ & 12.3 & 11.1 & 10.3 & 14.7 & 4.8 & 14.7 \\
$90^{\circ}$ & 12.3 & 10.3 & 8.7 & 15.5 & 7.9 & 10.7 \\
Difference & 0.0 & +0.8 & +1.6 & -0.8 & -3.1 & +4.0 \\
& Total Errors in Prime and Target Blocks & \\
$150^{\circ}$ & 19.5 & 17.1 & 16.7 & 20.2 & 9.5 & 16.3 \\
$90^{\circ}$ & 19.8 & 14.3 & 15.1 & 19.5 & 12.7 & 16.7 \\
Difference & -0.3 & +2.8 & +1.6 & +0.7 & -3.2 & -0.4 \\
& \multicolumn{7}{c}{ Target Block } & Alone Errors & & \\
$150^{\circ}$ & 11.9 & 10.7 & 10.7 & 9.1 & 7.9 & 10.3 \\
$90^{\circ}$ & 10.3 & 6.4 & 8.3 & 10.7 & 7.5 & 8.3 \\
Difference & +1.6 & +4.3 & +2.4 & -1.6 & +0.4 & +2.0 \\
\hline
\end{tabular}

RTs to $150^{\circ}$ targets were slowest when the primes were $90^{\circ}$ views.

An ANOVA was also performed on the log-linear transformed error scores. The main effect of prime view was significant $\left[F_{1}(5,410)=3.814, p<.003 ; F_{2}(5,175)=\right.$ $4.055, p<.004]$, but target view was not significant $\left[F_{1}(1,82)=0.004, p>.9 ; F_{2}(1,35)=0.272, p>.6\right]$. The interaction of prime view $\times$ target view was not significant $\left[F_{1}(5,410)=0.685, p>.6 ; F_{2}(5,175)=0.404, p>\right.$ $.8]$. Overall, as in the prime block, there were fewer errors to trials primed by a $120^{\circ}$ view, as compared with trials primed by $0^{\circ}$ and $90^{\circ}$ views $(p<.01$, NewmanKeuls analysis) and by $30^{\circ}, 60^{\circ}$, and $150^{\circ}$ views (not significant for subjects, $p<.05$ for items).

In addition, the target block analyses were repeated, but including correctly named target trials, irrespective of whether the prime had been named correctly. The pattern of results across RTs was identical to that found for the first RT analysis. There were no significant effects in the error analysis. Thus, there was no indication of an illusory priming effect in the target block that was due to the elimination of more difficult items following prime block errors (see Wheeldon \& Monsell, 1992).

\section{Discussion}

The results from the prime block analysis support the results of Humphrey and Jolicoeur (1993). There was a disadvantage for the initial naming of foreshortened, as compared with nonforeshortened, views of objects. We can conclude that there are view effects on the initial naming of stimuli from familiar object categories, even when objects are depicted from an elevated angle so as to reduce the accretion and deletion of parts across different views. Note, however, that the effects are small and are basically confined to a foreshortened view disadvantage, relative to the other views examined here. The $0^{\circ}$ views also tended to be named more slowly than were other nonforeshortened views. However, this disadvantage could have been an artifact of the stimuli used, since all views were scaled to occupy a $6 \times 6 \mathrm{~cm}$ square. After scaling, the $0^{\circ}$ views were disproportionately small in area, and some details were lost or were very small for these views, relative to other views. In Experiments 2 and 3 , the effects of view in depth on naming were enhanced by presenting highly foreshortened views. This allowed a more detailed investigation of the nature of the foreshortened view disadvantage revealed in Experiment 1.

Importantly, the analysis of priming indicated that, for a given target object, naming was sensitive to which prime view of that object had been presented. There was a significant quadratic component to the data for subjects who received $90^{\circ}$ targets and for subjects who received $150^{\circ}$ targets, reflecting the increasingly slow naming of targets primed by stimuli that were increasingly dissimilar to the target (see Figure 2). Note that the results implicate combined view- and object-specific priming effects. For a particular object, a very different pattern of results was obtained that was dependent on which prime and target views were presented. For example, if an object was named at a $150^{\circ}$ view in the prime block, it was named faster if it was again presented at a $150^{\circ}$ view in the target block (mean, $830 \mathrm{msec}$ ), compared with if it was presented at a $90^{\circ}$ target view $(874 \mathrm{msec})$. However, if an object was initially named at a $90^{\circ}$ prime view, it was named more efficiently at a subsequent $90^{\circ}$ target view $(822 \mathrm{msec})$ than at a $150^{\circ}$ target view $(874 \mathrm{msec})$. Note that the $x$-axis of Figure 2 plots the prime view of an object presented, and that the two lower lines of the figure plot responses to identical target views (either all $90^{\circ}$ or all $150^{\circ}$ target views); hence, the differences between the points along the lower two lines were due solely to the prior experience of the subjects with a particular set of objects in the prime block.

These results cannot be given an a priori explanation by theories that propose that effects of viewpoint are solely a result of early visual processes common to all objects - for example, because of variation in encoding efficiency prior to matching to stored knowledge (see, e.g., Marr, 1982). Any priming of early, general encoding procedures should have had equivalent effects on all targets presented at a given view and should not have varied as a function of whether particular target objects had appeared as primes in those views. However this prediction was not supported. Naming of a given target object was affected by the earlier prime view of the object presented. Indeed, naming a foreshortened, $90^{\circ}$ view in the prime block was sufficient to reverse the $90^{\circ}$ view disadvantage for that object in the target block, although there remained a substantial disadvantage for $90^{\circ}$ targets seen earlier as $0^{\circ}$ primes (see Figure 2). Similarly, in a sequential picture-picture matching task (Lawson \& Humphreys, 1996), we reported that matching was faster if both pictures depicted the same or similar views of an object, independent of the initial ease of recognition of 
the individual views. In that study, pairs of identical views (both $90^{\circ}$ or both $150^{\circ}$ ) and pairs of similar views $\left(90^{\circ}\right.$ and $60^{\circ} ; 150^{\circ}$ and $180^{\circ}$ ) were matched more efficiently than were pairs of dissimilar views $\left(90^{\circ}\right.$ and $180^{\circ} ; 150^{\circ}$ and $60^{\circ}$ ).

Interestingly, the degree of view sensitivity found in Experiment 1 suggests that, if view-invariant object recognition is achieved, it is only over a narrow range of views. We return to this point after Experiments 2 and 3, which examined the effects of even smaller $\left(10^{\circ}\right)$ rotations in depth.

The results from Experiment 1 provide support for theories that propose that the visual system employs viewspecific object representations to achieve recognition. When primes and targets are more similar, there is greater priming, because similar primes and targets are more likely to map onto the same stored view-specific representation (see, e.g., Tarr \& Pinker, 1989).

Interestingly, $150^{\circ}$ targets were primed by $0^{\circ}$ and $30^{\circ}$ views as strongly as by identical $150^{\circ}$ prime views. If it were only the physical rotation in depth between the prime and targets that determined the magnitude of priming, the naming of $150^{\circ}$ targets primed by $150^{\circ}, 120^{\circ}, 90^{\circ}$, $60^{\circ}, 30^{\circ}$, and $0^{\circ}$ views should be increasingly slow. Instead, we observed a quadratic function, with $150^{\circ}$ targets primed by $90^{\circ}$ views being named more slowly than $150^{\circ}$ targets primed by any other view. The present results are, therefore, inconsistent with theories that predict that the physical rotation of the stimulus is the sole determinant of view-specific effects-for example, simple mental rotation models. Note that around two-thirds of the objects presented were bilaterally symmetrical, and most of the remaining objects were almost bilaterally symmetrical, so that $30^{\circ}$ and $150^{\circ}$ views were usually mirror images of each other and, therefore, would reveal identical parts, features, and occluding contour (bar a mirrorimage reflection).

\section{EXPERIMENT 2}

The results from the prime block of Experiment 1 revealed that the initial naming of pictures was sensitive to view and, specifically, that the naming of foreshortened, $90^{\circ}$ views was disadvantaged. Experiment 2 extended that study, in order to investigate the cause and the extent of the foreshortened view disadvantage. In Experiment 1, $60^{\circ}$ and $120^{\circ}$ partially foreshortened views were named at least as efficiently as other, less foreshortened views $\left(0^{\circ}, 30^{\circ}\right.$, and $\left.150^{\circ}\right)$. The difference between the recognition efficiency of partially foreshortened $60^{\circ}$ and $120^{\circ}$ views and the more foreshortened $90^{\circ}$ views could be a result of a number of different factors-for instance, feature or part occlusion, symmetry, or occluding contour changes - or because foreshortened, $90^{\circ}$ views tend to reveal only a single (front or rear) surface of an object and so appear more two-dimensional than do partially foreshortened views. Which factors cause the foreshortened view disadvantage? Pertinent to this question is the form of the function relating the recognition efficiency of nonforeshortened, partially foreshortened, and fully foreshortened views. Does the foreshortened view disadvantage dissipate rapidly with decreasing foreshortening, or is there a more gradual decline in the effects of foreshortening?

The former case, of a highly tuned disadvantage for fully foreshortened views only, would suggest that there is a specific problem in recognizing $90^{\circ}$ views, caused by a catastrophic visual change for fully foreshortened views of objects. For example, fully foreshortened views commonly possess strong vertical (and often horizontal) symmetry, which is lost very rapidly as the object is rotated in depth away from the fully foreshortened view. Symmetry may be coded prominently in image descriptions of fully foreshortened views, but, because the symmetry is only present for such highly unusual, unstable views, it is not likely to be encoded in any stored object representations. This would result in a poor match between the image description of the fully foreshortened view and the stored object representation. In addition, fully foreshortened views (and views with the main axis fully exposed) often reveal only a single surface and appear more two-dimensional, relative to partly foreshortened views. If three-dimensional structural information is important for object recognition (Enns \& Rensink, 1990a, 1990b, 1991), the relative lack of this information would result in a specific disadvantage for the recognition of fully foreshortened, as compared with partially foreshortened, views.

In contrast, if increasingly foreshortened views become more difficult to recognize over a range of partially foreshortened views, this would suggest that there are one or more factors that influence the recognition of all foreshortened views, with the magnitude of the factor(s) varying monotonically as foreshortening increases. For example, the occluding contour generally changes smoothly and gradually as an object rotates in depth. Furthermore, the occluding contour of foreshortened views is often uninformative about object identity, whereas the occluding contour of nonforeshortened views generally appears to provide sufficient information for accurate recognition (Hayward, 1998; Lawson \& Humphreys, in press). If the foreshortened view disadvantage is caused by difficulties in recognizing the object from occluding contour information, a smooth, monotonic decrease in the ease of recognition with increasing foreshortening would be predicted. Similarly, important distinguishing features and parts are more likely to be occluded as an object becomes more foreshortened. If recognition is based on the availability of these features and parts - for instance, as Biederman (1987) proposes - then, again, recognition should be increasingly difficult for increasingly foreshortened views.

An investigation into the nature and extent of the foreshortened view disadvantage was conducted in Experiment 2. The subjects named a set of familiar objects once only. All objects were depicted from a foreshortened 
viewpoint, from partially foreshortened $\left(60^{\circ}, 70^{\circ}, 80^{\circ}\right)$ to fully foreshortened $\left(90^{\circ}\right)$ views (see Figure 3 ). Unlike the stimuli used in Experiment 1, objects were depicted from a nonelevated angle; so, the fully foreshortened $90^{\circ}$ view used in Experiment 2 was more strongly foreshortened than the $90^{\circ}$ view presented in Experiment 1. The $90^{\circ}$ view revealed little or no upper or side surface information and often appeared two-dimensional (see Figure 1).

\section{Method}

Subjects. There were 64 subjects, who were paid to participate. Materials. A set of four views of each of 72 common, everyday objects was produced (see Appendix B). The objects were taken from four broadly defined categories: animals, vehicles, household items, and machines. Unlike the objects presented in Experiment 1, no object was strongly elongated, and there was a low aspect ratio for all views of every object. The low aspect ratio reduced variation in the area of the different depicted views of a given object, which was a potential confound with the stimuli presented in Experiment 1 . The angle of view was defined with respect to the line of sight of the viewer, relative to the main axis of the object, as for the first set of stimuli (see Experiment 1, Materials). The main axis was defined as being the most elongated axis or the main axis of symmetry of the object. Objects were rotated about the vertical axis running through their center point. The four views of each object were $60^{\circ}, 70^{\circ}, 80^{\circ}$, and $90^{\circ}$; thus, all views were partially or fully foreshortened (see Figure 3).

The stimuli were line drawings, produced by tracing and then scanning photographs or scale models of the objects. Unlike the first set of stimuli, the photographs were taken from a position that was both vertically and horizontally aligned with the center of the object. Thus, the object was fully foreshortened in the $90^{\circ} \mathrm{view}$, and the effects of foreshortening were more severe than for the initial set of stimuli tested in Experiment 1 (see Figure 1). Each picture was scaled to occupy a square of $6 \times 6 \mathrm{~cm}$.

Design. On each trial, a picture of an object was presented at $60^{\circ}$, $70^{\circ}, 80^{\circ}$, or $90^{\circ}$. The subjects completed one block of trials only, consisting of one view of each of the 72 objects. There were four different picture sets. In each picture set, 18 of the 72 objects were shown at each of the four different views. The set of 18 objects shown at each view was rotated in a Latin Square design across the four different picture sets, so that, over the four sets, each object was seen four times, once at each view. Sixteen subjects were assigned to each picture set. The order of presentation of trials within a block was random and was different for each subject.

Apparatus and Procedure. These were identical to those in Experiment 1 .

\section{Results}

Response latencies less than $300 \mathrm{msec}$ or exceeding $5,000 \mathrm{msec}$ were discarded as errors. In addition, trials in which subjects used an inappropriate name or in which the microphone was accidentally activated before the subject responded were discarded as errors. All subjects scoring over $40 \%$ errors across the 72 objects in the experiment were replaced ( 6 subjects).

Mean correct RTs over subjects are shown in Figure 4; errors are given in Table 2 . In the items analysis, there were a small number of empty cells that were replaced by the mean for that condition. An ANOVA was carried out on the mean correct naming RTs. There was one withinsubjects factor, view $\left(60^{\circ}, 70^{\circ}, 80^{\circ}\right.$, or $\left.90^{\circ}\right)$.
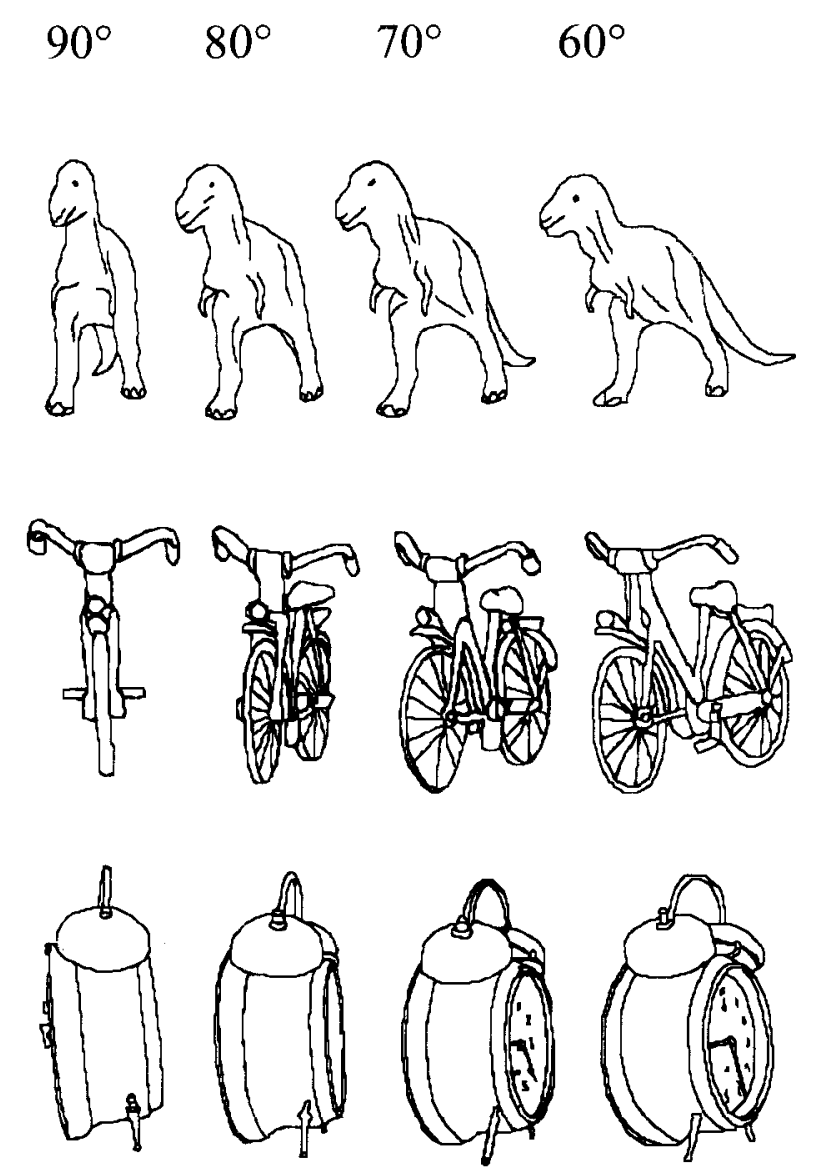

Figure 3. Examples of the four different views of the dinosaur, bicycle, and clock presented in Experiments 2 and 3.

The effect of view was significant $\left[F_{1}(3,189)=18.817\right.$, $\left.p<.001 ; F_{2}(3,213)=14.825, p<.001\right]$. The $90^{\circ}$ views were named more slowly than were $80^{\circ}$ views $(p<.01$, Newman-Keuls analysis), which in turn tended to be named more slowly than were $70^{\circ}$ views $(p<.01$ for subjects; not significant for items) and $60^{\circ}$ views $(p<.05)$. There was no significant difference in naming latencies between $70^{\circ}$ and $60^{\circ}$ views.

An ANOVA was also performed on the log-linear transformed error scores. The effect of view was significant $\left[F_{1}(3,189)=93.278, p<.001 ; F_{2}(3,213)=39.344, p<\right.$ $.001]$. More errors were made when naming $90^{\circ}$ views, as compared with $80^{\circ}$ views $(p<.01$, Newman-Keuls analysis), to which, in turn, more errors were made, as compared with $70^{\circ}$ and $60^{\circ}$ views $(p<.05)$. There was no significant difference in the error rates for $70^{\circ}$ and $60^{\circ}$ views.

\section{Discussion}

The results clearly revealed that, across the $70^{\circ}, 80^{\circ}$, and $90^{\circ}$ views, objects were named increasingly slowly and decreasingly accurately as they became more foreshortened. However, there was no significant difference in the naming efficiency of the $60^{\circ}$ and $70^{\circ}$ views. Thus, 


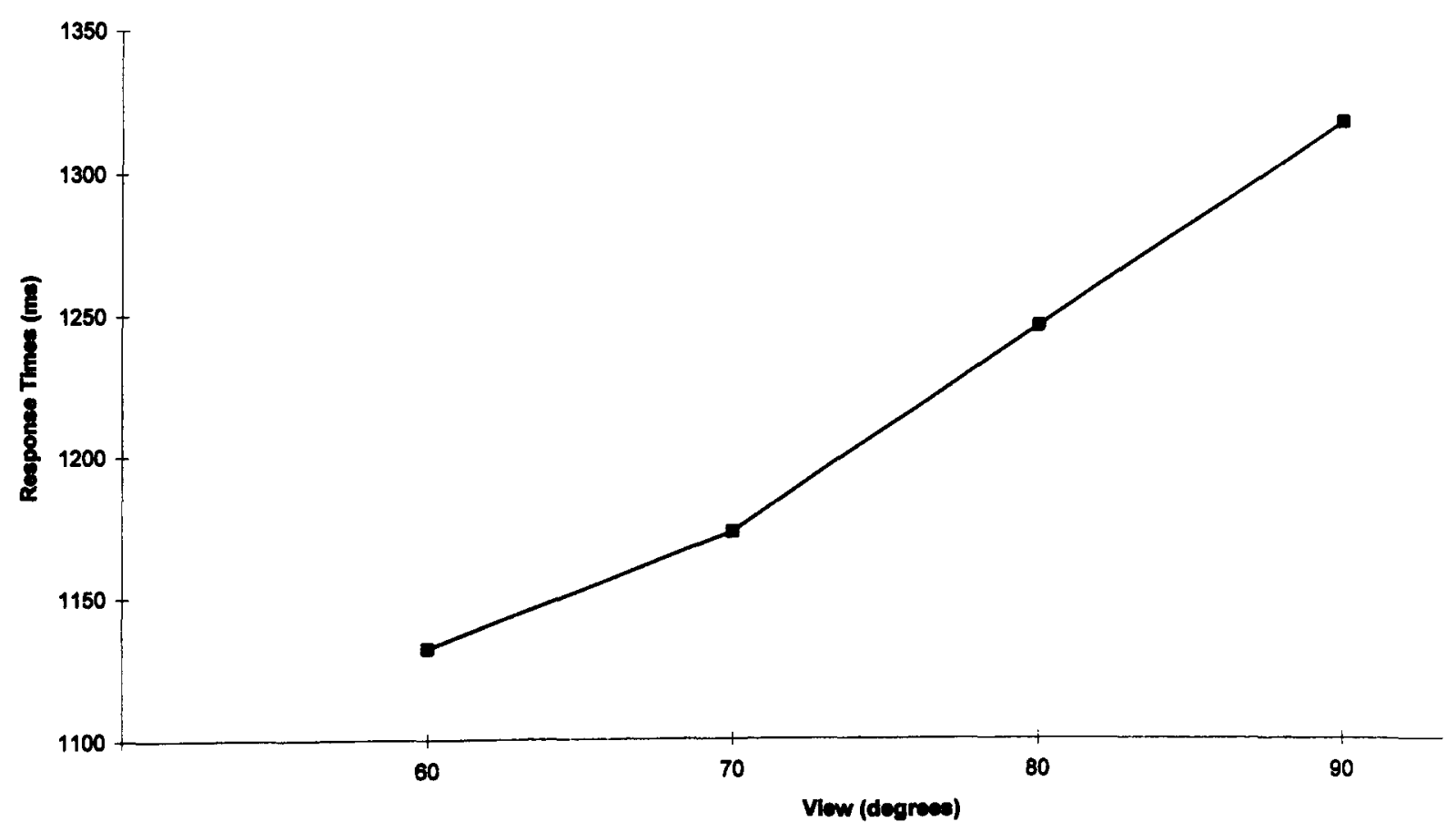

Figure 4. Mean correct response times as a function of view, in Experiment 2.

the fully foreshortened view was not uniquely difficult to recognize; partially foreshortened views were also hard to recognize. The monotonic relationship between the degree of foreshortening of a stimulus and its ease of recognition, for the $70^{\circ}, 80^{\circ}$, and $90^{\circ}$ views, suggests that a common factor, or set of factors, varies as a depicted object is rotated in depth to become foreshortened-for example, the occluding contour of the object or the visibility of an object's features and parts. The results refute the hypothesis that the foreshortened view disadvantage is caused only by a catastrophic visual change in the image for the fully foreshortened view, as compared with partially foreshortened views - for example, because of the strong symmetry or the two-dimensional appearance of fully foreshortened views.

\section{EXPERIMENT 3}

In Experiment 3, the effect of a prime on the efficiency of naming a subsequent target view of the same object was investigated as it was in Experiment 1. However, the stimuli presented in Experiment 3 were the same highly foreshortened views of objects as those used in Experiment 2 . Thus, the difference in the angle of rotation be-

Table 2

Mean Error Rates (\%) as a Function of Picture View, in Experiment 2

\begin{tabular}{ccccc}
\hline & \multicolumn{4}{c}{ Picture View } \\
\cline { 2 - 5 } & $60^{\circ}$ & $70^{\circ}$ & $80^{\circ}$ & $90^{\circ}$ \\
\hline Percentage errors & 12.3 & 12.7 & 18.8 & 38.7 \\
\hline
\end{tabular}

tween adjacent views was much smaller here than in Experiment 1 , being only $10^{\circ}$, as compared with $30^{\circ}$ earlier. This is important, given the results of Experiment 1 , which revealed that the efficiency of naming a target view was influenced by which view of the object had previously been named in the prime block. Experiment 3 attempted, first, to replicate the results reported in Experiment 1 , using a new set of objects depicted from a different range of views. Second, Experiment 3 extended Experiment 1 , in investigating the degree of sensitivity of target naming to the view of the prime-was the amount of priming observed significantly different for targets rotated by just $10^{\circ}$ in depth from each other?

\section{Method}

Subjects. There were 56 subjects, who were paid to participate. No subject had participated in Experiment 2.

Materials. The $60^{\circ}, 70^{\circ}, 80^{\circ}$, and $90^{\circ}$ views of 64 of the 72 objects used in Experiment 2 were used (the following eight items were tested but were not included in the analyses of results of Experiment 3, because of an error in counterbalancing: corkscrew, deer, dinghy, hair clip, hovercraft, paperclip, pint glass, and wardrobe).

Design. On each trial, a picture of an object was presented at $60^{\circ}$, $70^{\circ}, 80^{\circ}$, or $90^{\circ}$. Each subject saw one view of each of the $64 \mathrm{ob}-$ jects in each block. The subjects completed five blocks of trials, three practice blocks, followed by a prime and finally a target block. The practice blocks were included in order to try to improve subject's accuracy in the two experimental blocks, since Experiment 2 had revealed the difficulty in naming these stimuli on initial presentation. For a given subject, the practice and prime blocks were identical. For the practice and prime blocks, there were two different picture sets. In each picture set, 32 of the 64 objects were shown at $60^{\circ}$ and 32 at $90^{\circ}$. A given object was presented at $60^{\circ}$ in one picture set and at $90^{\circ}$ in the other set. Twenty-eight subjects were as- 
signed to each of the two prime picture sets. Each group of 28 subjects was divided into four subgroups, each with 7 subjects, and each subgroup was assigned to a different target picture set. In each of the four target picture sets, 16 of the 64 objects were shown at each of four different views- $60^{\circ}, 70^{\circ}, 80^{\circ}$, and $90^{\circ}$. Of these $16 \mathrm{ob}-$ jects, 8 had been seen at $60^{\circ}$ and 8 at $90^{\circ}$ in the prior prime and practice blocks. The set of objects shown at each view was rotated in a Latin Square design across the different target picture sets, so that over all four target picture sets, each object was seen four times, once at each view. The order of presentation of trials within a block was random and was different for each subject.

Apparatus and Procedure. These were identical to those in Experiment 1 , except that, in the three practice blocks, if subjects named an object incorrectly, they were told the correct name. No feedback was given in the prime and target blocks.

\section{Results}

Errors were scored as in Experiment 1. No subject scored over $33 \%$ errors across the 64 objects in the experiment, and so no subjects were replaced. An error for a given object was included if it occurred in the prime or in the target block or in both blocks, so that, for at least 43 of the 64 objects, all of the subjects named the object correctly in both the prime and the target block.

Mean correct RTs over subjects in the prime and target blocks are shown in Figure 5; errors are given in Table 3. Separate ANOVAs were conducted on the results from the prime and the target blocks.

To illustrate the importance of the initial practice blocks in Experiment 3, Figures 6A and 6B give the mean RTs and percentage errors, respectively, for Experiment 2 and for the prime and target blocks in Experiment 3, plotted as a function of whether a $60^{\circ}$ or a $90^{\circ}$ view was presented on a given trial. Note that, in Experiment 2, relative to
Experiment 3, different subjects were tested, eight additional objects were included in the mean results, and no feedback was provided; thus, the results across the two experiments cannot be compared directly. However, it is clear that, for RTs and especially for errors, overall performance improved and the foreshortened view disadvantage was reduced as subjects gained experience with the experimental stimuli, from initial recognition (Experiment 2) to naming after completing three blocks of practice trials (in Experiment 3 ).

Prime block only analysis. For the analysis of the prime block alone, a trial was only discarded if an error occurred in the prime block. An ANOVA was conducted on the mean correct naming RTs. There was one withinsubjects factor, prime view (the view of the picture presented in the practice and prime blocks, $60^{\circ}$ or $90^{\circ}$ ).

The main effect of prime view was significant $\left[F_{1}(1,55)=108.805, p<.001 ; F_{2}(1,63)=35.207, p<\right.$ $.001]$. In the prime block, $60^{\circ}$ views were named more quickly than $90^{\circ}$ views. An ANOVA was also performed on the log-linear transformed error scores. The main effect of prime view was significant $\left[F_{1}(1,55)=5.231 p<\right.$ $\left..03 ; F_{2}(1,63)=4.313, p<.05\right]$. In the prime block, $60^{\circ}$ views were named more accurately than were $90^{\circ}$ views.

A second analysis of the prime block only data was conducted, including target view (the view of the picture presented in the target block, $60^{\circ}, 70^{\circ}, 80^{\circ}$, or $90^{\circ}$ ) as a within-subjects factor. There was no significant effect of target view, and there was no significant interaction of prime view $\times$ target view, for RTs or for errors. This analysis was conducted as a precautionary measure, and it provided no evidence to suggest that there was a differ-

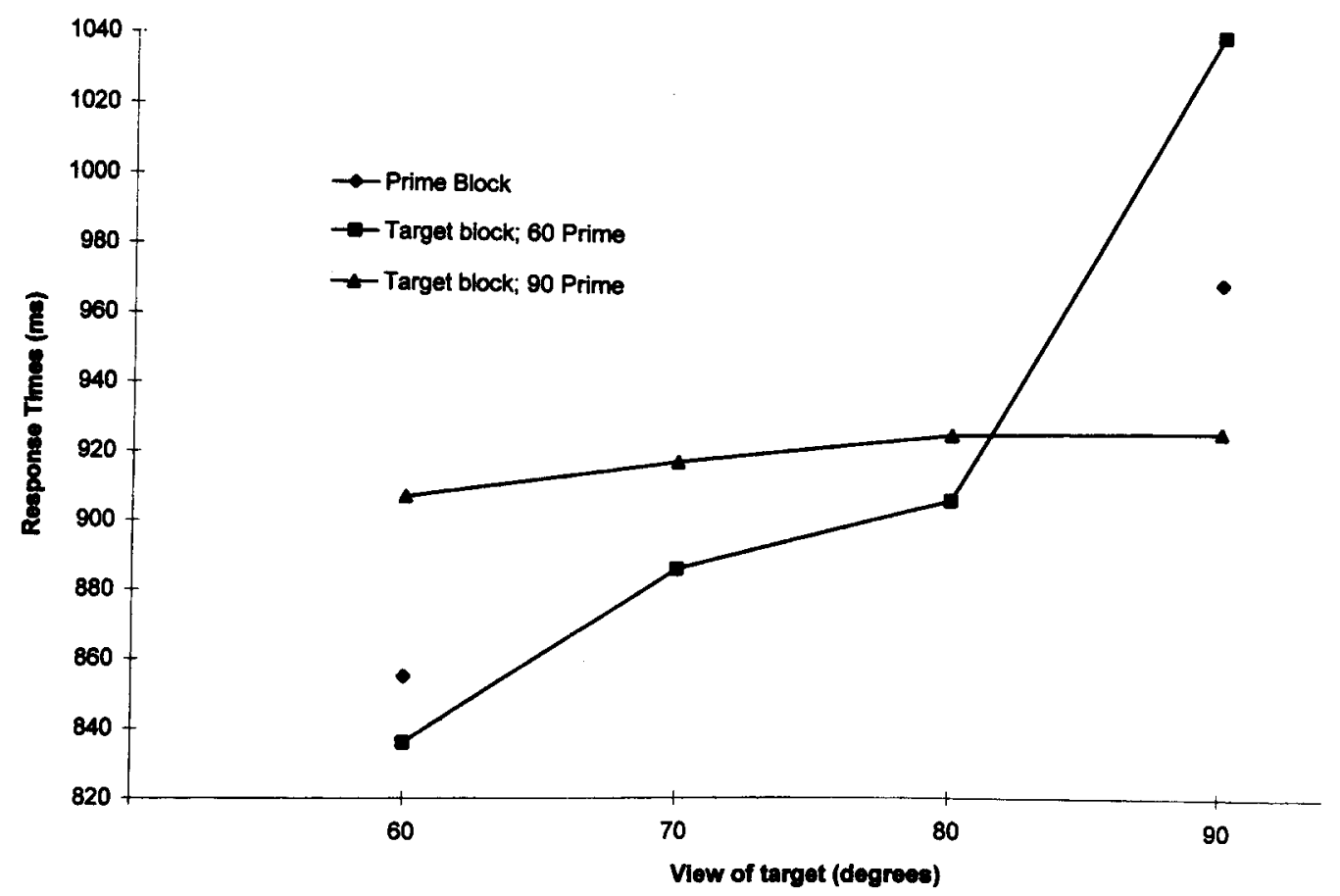

Figure 5. Mean correct response times for prime and target block trials in which the subject named the object correctly in both blocks, for $60^{\circ}$ and $90^{\circ}$ prime views, as a function of target view, in Experiment 3 . 
Table 3

Mean Error Rates (\%) for Errors Made in the Prime Block Alone (Used in the Prime Block Analysis), Errors Made to Objects in the Prime, the Target or in Both Blocks (Used in the Target Block Analysis), and Errors Made in the Target Block, Irrespective of the Errors Made in the Prime Block, as a Function of Prime and Target View in Experiment 3

\begin{tabular}{|c|c|c|c|c|}
\hline \multirow[b]{2}{*}{ Prime View } & \multicolumn{4}{|c|}{ Target View } \\
\hline & $60^{\circ}$ & $70^{\circ}$ & $80^{\circ}$ & $90^{\circ}$ \\
\hline \multicolumn{5}{|c|}{ Prime Block Alone Errors } \\
\hline $60^{\circ}$ & 3.4 & 3.8 & 4.0 & 3.4 \\
\hline $90^{\circ}$ & 3.8 & 5.4 & 5.8 & 6.5 \\
\hline Difference & -0.4 & -1.6 & -1.8 & -3.1 \\
\hline
\end{tabular}

Total Errors in Prime and Target Blocks

\begin{tabular}{|c|c|c|c|c|}
\hline $60^{\circ}$ & 5.6 & 7.6 & 9.4 & 14.5 \\
\hline $90^{\circ}$ & 8.3 & 9.6 & 9.6 & 8 \\
\hline Difference & -2.7 & -2.0 & -0.2 & +6.2 \\
\hline \multicolumn{5}{|c|}{ Target Block Alone Errors } \\
\hline $60^{\circ}$ & 2.2 & 3.8 & 6.3 & 12 \\
\hline $90^{\circ}$ & 5.4 & 5.6 & 4.0 & 3 \\
\hline Difference & -3.2 & -1.8 & +2.3 & +9 \\
\hline
\end{tabular}

ence in the prime block between the subjects assigned to the four different target view conditions.

Target block only analysis. For the analysis of the target block, a trial was discarded if the subject made an error in naming an object in either the prime block, the target block, or both blocks (see Table 3 ). In the items analysis, a small number of empty cells were replaced by the mean for that condition. An ANOVA was conducted on the mean correct naming RTs. There were two withinsubjects factors, prime view $\left(60^{\circ}\right.$ or $\left.90^{\circ}\right)$ and target view $\left(60^{\circ}, 70^{\circ}, 80^{\circ}\right.$, or $\left.90^{\circ}\right)$.

The main effect of prime view was not significant $\left[F_{1}(1,55)=0.036, p>.8 ; F_{2}(1,63)=0.059, p>.8\right]$, but target view was significant $\left[F_{1}(3,165)=25.701, p \leqslant .001\right.$; $\left.F_{2}(3,189)=21.174, p<.001\right]$. The $90^{\circ}$ targets were named more slowly than were the $80^{\circ}$ or $70^{\circ}$ targets $(p<.01$, Newman-Keuls analysis), which, in turn, were named more slowly than were the $60^{\circ}$ targets $(p<.05)$. The interaction of prime view $\times$ target view was also significant $\left[F_{1}(3,165)=15.989, p<.001 ; F_{2}(3,189)=23.145\right.$, $p<.001]$. The $90^{\circ}$ targets primed by $60^{\circ}$ views were named more slowly than was any other view $(p<.01$, NewmanKeuls analysis). In addition, the $60^{\circ}$ targets primed by $60^{\circ}$ views were named faster than was any other view $(p<.05$ for subjects, $p<.01$ for items). These results can be restated as follows: $90^{\circ}$ targets were named faster when preceded by $90^{\circ}$ primes than when preceded by $60^{\circ}$ primes $(p<.01)$; prime view $\left(60^{\circ}\right.$ or $\left.90^{\circ}\right)$ did not significantly influence the speed of naming $80^{\circ}$ and $70^{\circ}$ targets; finally, $60^{\circ}$ targets were named faster when preceded by $60^{\circ}$ primes than when preceded by $90^{\circ}$ primes $(p<.01)$.

An ANOVA was also performed on the log-linear transformed error scores. The main effect of prime view was not significant $\left[F_{1}(1,55)=0.134, p>.7 ; F_{2}(1,63)=\right.$ $0.165, p>.6]$, but target view was significant $\left[F_{1}(3,165)=\right.$ $\left.4.505, p<.005 ; F_{2}(3,189)=2.779, p<.05\right]$. The $90^{\circ}$ tar- gets were named less accurately than were the $60^{\circ}$ targets ( $p<.05$, Newman-Keuls analysis). The interaction of prime view $\times$ target view was significant across subjects only $\left[F_{1}(3,165)=4.023, p<.009 ; F_{2}(3,189)=1.708\right.$, $p>.1$ ]. For subjects only, $90^{\circ}$ targets primed by $60^{\circ}$ views were named less accurately than was any other view $(p<$ .05 ). No other comparison was significant.

In addition, the target block analyses were repeated, but correctly named targets were included irrespective of whether the prime had been named correctly. The pattern of results across RTs was identical to that found for the first RT analysis. In the error analysis, the effect of prime view was significant across subjects only $\left[F_{1}(1,55)=\right.$ $\left.5.087, p<.03 ; F_{2}(1,63)=2.423, p>.1\right]$. Targets primed by a $60^{\circ}$ view tended to be named less accurately than were targets primed by $90^{\circ}$ views. Target view was significant $\left[F_{1}(3,165)=4.781, p<.004 ; F_{2}(3,189)=\right.$ $2.944, p<.04]$. The $90^{\circ}$ targets were named less accurately than were $70^{\circ}$ and $80^{\circ}$ targets ( $p<.05$ for subjects, not significant for items; Newman-Keuls analysis) and $60^{\circ}$ targets $(p<.05)$. The interaction of prime view $\times$ target view was also significant $\left[F_{1}(3,165)=13.709\right.$, $\left.p<.001 ; F_{2}(3,189)=9.050, p<.001\right]$. The $90^{\circ}$ targets primed by $60^{\circ}$ views were named less accurately than was any other view $(p<.01$ for subjects, $p<.05$ for items). Thus, there was no indication of bias or confound effects in the first target block analysis, because of target trials being eliminated following prime block errors.

\section{Discussion}

The results from the prime block revealed strong effects of view, with a clear advantage for naming $60^{\circ}$ views over $90^{\circ}$ views, for both RTs and errors. This effect of view persisted, despite three prior practice blocks in which the subjects had named stimuli that were identical to those presented in the prime block and had been given feedback after incorrect responses. The view effect was also still present in the target block of Experiment 3, when comparing the efficiency of naming $60^{\circ}$ views, relative to $90^{\circ}$ views, after priming by identical views $\left(60^{\circ}\right.$ and $90^{\circ}$, respectively; see Figure 6). However, in Experiment 3, relative to Experiment 2, the foreshortened view disadvantage did reduce, for RTs (see Figure 6A) and, especially, for errors (see Figure 6B). The disadvantage for naming a $90^{\circ}$, as compared with a $60^{\circ}$, view was around $200 \mathrm{msec}$ on RTs and $26 \%$ on errors on initial naming ( $\mathrm{Ex}$ periment 2), but only around $115 \mathrm{msec}$ on RTs and $2 \%$ on errors after three practice blocks of naming with feedback (prime block of Experiment 3 ). This still significant but reduced effect of view after practice is similar to that reported for the repeated naming of plane disoriented views of familiar objects (Jolicoeur, 1985; Jolicoeur \& Milliken, 1989).

The results from the target block analysis of Experiment 3 fully concur with the results obtained from Experiment 1 . In both experiments, increased priming was observed when the prime and target were more similar in view. Indeed, in Experiment 3, priming was significantly 

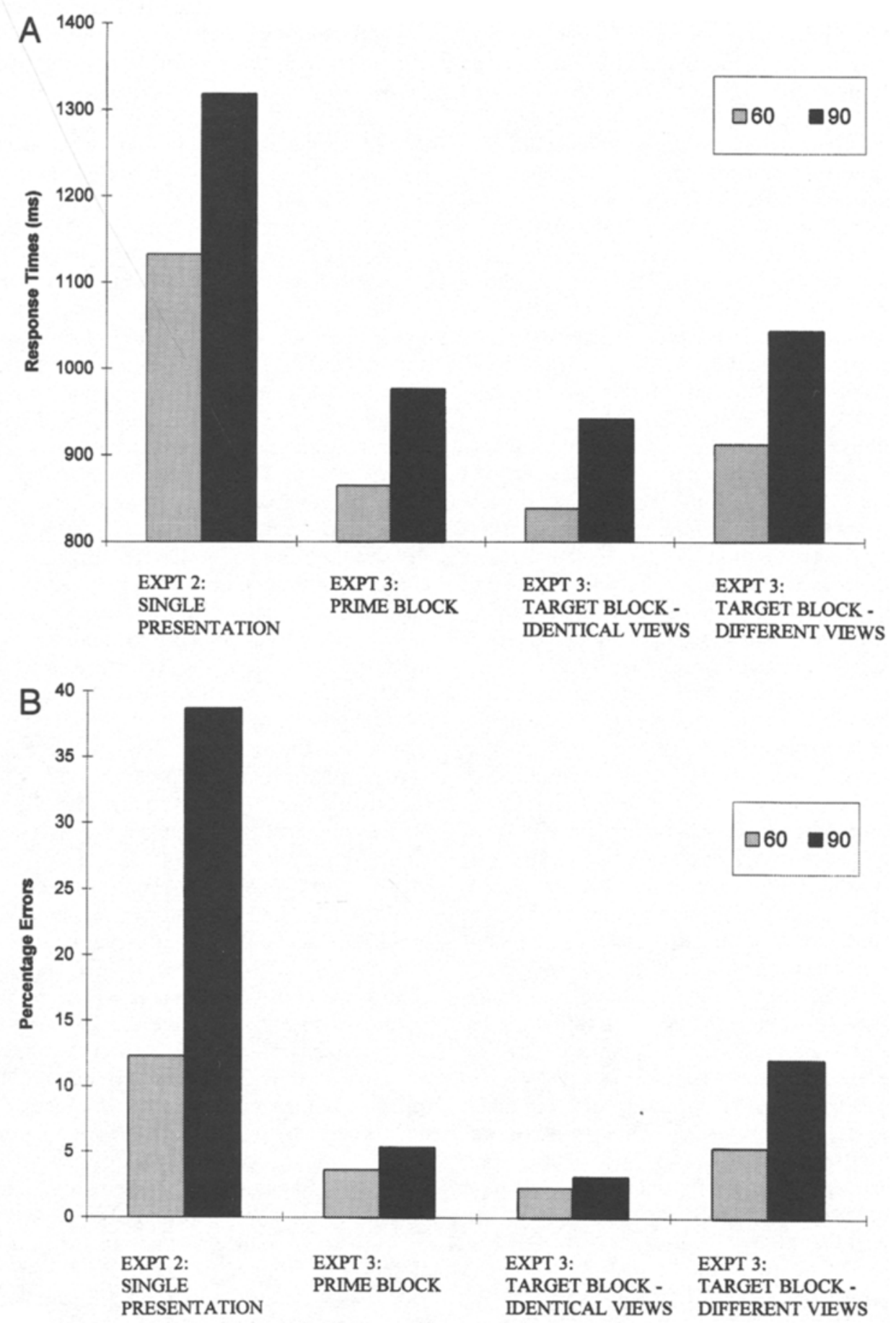

Figure 6. Mean correct response times $(A)$ and percentage errors, ignoring any errors made in earlier blocks (B), as a function of the view of the object being named, either $60^{\circ}$ or $90^{\circ}$. Results are presented for Experiment 2 (on initial presentation of the stimuli, for 72 objects, with no response feedback provided) and for Experiment 3 (on the fourth, prime, and fifth target presentations of the stimuli, for 64 of the 72 objects presented in Experiment 2, with the correct response provided as feedback to incorrect responses during the initial three practice presentations only). For a given object in Experiment 3, in the prime block results, the subjects were naming an identical view for the fourth time; in the target block identical results, the subjects were naming an identical view for the fifth time; and in the target block different results, the subjects were naming a $60^{\circ}$ view after four blocks of naming a $90^{\circ}$ view, or they were naming a $90^{\circ}$ view after four blocks of naming a $60^{\circ}$ view. 
influenced by as little as a $10^{\circ}$ rotation in depth. Note that, in Figure 5, it might appear that, for foreshortened, $90^{\circ}$ primes, there was little effect of the prime view on the naming of target views and that only for $60^{\circ}$ prime views was there a strong effect of prime view on the naming of target views. However, this is a misleading description of the results, since there was a large baseline difference between the efficiency of naming $60^{\circ}$ and $90^{\circ}$ views (see above; see also Figures $6 \mathrm{~A}$ and $6 \mathrm{~B}$ ). When this baseline difference is taken into consideration, it is clear that there was a strong priming effect for foreshortened, $90^{\circ}$ target views that were preceded by $90^{\circ}$ prime views in Experiment 3. This resulted in $90^{\circ}$ target views being named just as efficiently as less foreshortened and more canonical $60^{\circ}, 70^{\circ}$, and $80^{\circ}$ targets that had also been preceded by a $90^{\circ}$ prime (see Figure 5).

Supporting the conclusions drawn from Experiment 1, the view effects found in the target block of Experiment 3 cannot be accounted for solely in terms of the absolute canonicality or goodness of the target views. Foreshortened $90^{\circ}$ targets were named as efficiently as more canonical targets when they had previously been seen as foreshortened primes. These results also preclude an explanation wholly in terms of subjects' developing a general compensation strategy to cope with image foreshortening, during the course of the practice and prime blocks of Experiment 3. There was still a strong foreshortened view disadvantage for those $90^{\circ}$ target view objects that had previously been named at $60^{\circ}$ views in the practice and prime blocks.

The present combined view- and object-specific priming effects provide evidence against any claim of general view invariance in the recognition of familiar objects. Instead, our results are consistent with a number of recent studies that have demonstrated highly view-specific recognition of novel objects (see, e.g., Bülthoff \& Edelman, 1992; Edelman \& Bülthoff, 1992; Humphrey \& Khan, 1992; Rock \& Di Vita, 1987), while extending these results to the case of familiar objects. The results provide support to theories that propose that multiple view-specific object representations are stored (see, e.g., Tarr \& Pinker, 1989). Optimal priming with such representations requires that a given familiar object is depicted from within a relatively narrow range of similar views. This priming leads to more efficient identification of a subsequent, similar target view of that object.

\section{GENERAL DISCUSSION}

The results of the three picture-naming experiments reported here allow us to draw a number of conclusions about the effects of depth rotation on the efficiency of object recognition. First, foreshortened views were relatively difficult to name when pictures were first presented (Experiments 1 and 2), and, for a narrow range of highly foreshortened views, initial naming latencies and errors increased with increasing foreshortening (Experiment 2 ). These results support previous experimental and neuropsychological findings, in demonstrating that foreshort- ened views are particularly difficult to recognize (Humphrey \& Jolicoeur, 1993; Humphreys \& Riddoch, 1984; Srinivas, 1993; Warrington \& Taylor, 1973, 1978). Furthermore, the monotonic increase in naming latencies across $70^{\circ}, 80^{\circ}$, and $90^{\circ}$ views (Experiment 2) suggests that there is a common difficulty in the recognition of both partially and fully foreshortened views. The nature of this problem has not been fully specified as yet. From the results of Humphrey and Jolicoeur, it does not appear to be due solely to the deletion of parts, since they found a foreshortened view disadvantage for stimuli in which all the major parts of an object remained visible. An alternative is that representations of foreshortened views are not stored, as these views are uncommon and unstable across viewpoint shifts. For recognition to take place, images of foreshortened views must be transformed prior to matching to more canonical view-specific stored representations.

Second, in Experiments 1 and 3, the view of a prime influenced strongly the ease of naming a target view of the same object presented several minutes later. This contrasts with a number of earlier reports that have emphasized the relative insensitivity of priming to visual similarity for both objects and faces (Biederman \& Gerhardstein, 1993; Bruce \& Valentine, 1985; Brunas et al., 1990; Brunas-Wagstaff et al., 1992; Johnston et al., 1996; Warren \& Morton, 1982). However, in Experiment 3 here, even $10^{\circ}$ rotations in depth between primes and targets significantly affected the efficiency of target naming. In addition, in both Experiments 1 and 3, the foreshortened view disadvantage was eliminated completely by priming from a foreshortened view. Finally, in Experiment 1 , we found that priming was not tied to the particular mirror-image version of a stimulus that had been presented. Identical and mirror-image primes were equally effective, indicating that view-specific effects were not simply tied to the difference in physical rotation between prime and target views. Overall, for a given object, priming increased as the similarity between the prime and target increased, and this priming extended over several minutes. The temporal separation between primes and targets here was similar to that in prior studies of priming (see, e.g., Biederman \& Gerhardstein, 1993). The priming effects that we have observed are therefore relatively long term, view specific, and object specific.

Why have we observed strong view-specific priming effects here, when previous investigations have reported relatively weak or nonexistent effects? We suggest that, relative to most earlier experiments, our studies were more sensitive to the effects of rotation in depth. Our experiments were designed to specifically investigate this issue; we used large numbers of both subjects and items; we carefully manipulated view in depth over a range of views; and we analyzed over both subjects and items. Priming of picture naming produces relatively noisy data, and it can be difficult to demonstrate clear effects without the above measures being taken. In addition, we note that marginal effects of depth rotation were obtained in Experiment 1 of Biederman and Gerhardstein (1993). 
However, we should also emphasize that our results suggest that subjects do benefit greatly from generalizing prior experience across different views. Figures 2 (from Experiment 1) and 6 (from Experiments 2 and 3 ) indicate a clear overall improvement in performance with experience in naming the same object, even when that object is presented in different prime and target views. In this paper, we have concentrated on the theoretically revealing view-specific benefit for prior identical presentations of the target, relative to prior presentations of a different view to the target. However, we should not overlook our ecologically important ability to take advantage of the prior identification of a familiar object from a different view in depth. Generalization over view can be accounted for within a view-specific framework, if it is assumed that a given view may be matched to more than one stored, view-specific representation. In this case, priming may benefit nonidentical (and even visually dissimilar) target views, although such priming should be reduced relative to that observed for identical target views. In addition, semantic and name priming would probably have increased object-specific but non-view-specific priming levels in Experiments 1 and 3.

Overall, these results can be taken as evidence against theories that propose that all view effects on recognition are a result of variation in early, general encoding stages of visual processing, prior to accessing stored object representations (see, e.g., Marr, 1982). The results also provide evidence against theories that predict that object recognition is largely view invariant. Instead, the results indicate that highly view-specific object representations are stored. If two views of the same object are dissimilar, they may activate different image descriptions, which, in turn, may be matched to different view-specific stored object representations. Priming will then be reduced, relative to when two views are sufficiently similar to be matched to the same view-specific stored representation. Note that the present results indicate that stored object representations must be tightly bound to specific viewpoints, since even $10^{\circ}$ rotations in depth in Experiments 2 and 3 influenced the efficiency of identification and priming. It is likely that this view specificity is particularly highly tuned around certain critical views--for instance, as a result of foreshortening. Thus, the data demonstrate that, for critical vantage points, there is a high degree of dependence of object recognition on subjects' experience with particular views of specific objects.

\section{REFERENCES}

BARTRAM, D. J. (1974). The role of visual and semantic codes in object naming. Cognitive Psychology, 6, 325-356.

Biederman, I. (1987). Recognition-by-components: A theory of human image understanding. Psychological Review, 94, 115-147.

Biederman, I., \& CoOPER, E. E. (1991a). Evidence for complete translational and reflectional invariance in visual object priming. Perception, 20, 585-593.

Biederman, 1., \& CoOper, E. E. (1991b). Object recognition and later ality: Null effects. Neuropsuchologia, 29, 685-694.
Biederman, I., \& CoOper, E. E. (1992). Size invariance in visual object priming. Journal of Experimental Psychology: Learning, Memory, \& Cognition, 13, 640-645.

Biederman, I., \& Gerhardstein, P. C. (1993). Recognizing depthrotated objects: Evidence and conditions for three-dimensional viewpoint invariance. Journal of Experimental Psychology: Human Perception \& Performance, 19, 1162-1182.

Biederman, I., \& Gerhardstein, P. C. (1995). Viewpoint-dependent mechanisms in visual object recognition: Reply to Tarr and Bülthoff (1995). Journal of Experimental Psychology: Human Perception \& Performance, 21, 1506-15]4

BrUCE, V., \& VALENTINE, T. (1985). Identity priming in the recognition of familiar faces. British Journal of Psychology, 76, 373-383.

BRunas, J., YounG, A. W., \& Ellis, A. W. (1990). Repetition priming from incomplete faces: Evidence for part to whole completion. British Journal of Psychology, 81, 43-56.

Brunas-WagstafF, J., Young, A. W., \& Ellis, A. W. (1992). Repetition priming follows spontaneous but not prompted recognition of familiar faces. Quarterly Journal of Experimental Psychology, 44A, 423-454.

BÜlthoff, H. H., \& Edelman, S. (1992). Psychophysical support for a 2-D view interpolation theory of object recognition. Proceedings of the National Academy of Sciences, 89, 60-64.

Edelman, S., \& BülthoFf, H. H. (1992). Orientation dependence in the recognition of familiar and novel views of three-dimensional objects. Vision Research, 32, 2385-2400.

Eluis, A. W., Young, A. W., Flude, B. M., \& Hay, D. C. (1987). Repetition priming of face recognition. Quarterly Journal of Experimental Psychology, 39A, 193-210.

Ellis, R., Allport, D. A., Humphreys, G. W., \& Collis, J. (1989). Varieties of object constancy. Quarterly Journal of Experimental Psychology, 41A, 775-796.

ENNS, J. T., \& RENSINK, R. A. (1990a). Influence of scene-based properties on visual search. Science, 247, 721-723.

EnNs, J. T., \& RENSINK, R. A. (1990b). Sensitivity to 3-D orientation in visual search. Psychological Science, 1, 323-326.

EnNs, J. T., \& RenSink, R. A. (1991). Preattentive recovery of 3-D orientation from line drawings. Psychological Review, 98, 335-351.

Farah, M. J., Rochlin, R., \& Klein, K. L. (1994). Orientation invariance and geometric primitives in shape recognition. Cognitive Science, 18, 325-344.

HAYWARD, W. G. (1998). Effects of outline shape in object recognition. Journal of Experimental Psychology: Human Perception \& Performance, 24, 427-440.

HUMPHREY, G. K., \& JOLICOEUR, P. (1988). Visual object identification: Some effects of image foreshortening and monocular depth cues. In Z. W. Pylyshyn (Ed.), Computational processes in human vision: An interdisciplinary perspective (pp. 429-442). Norwood, NJ: Ablex.

HuMPhrey, G. K., \& Jolicoeur, P. (1993). Visual object identification: Some effects of image foreshortening, monocular depth cues, and visual field on object identification. Quarterly Journal of Experimental Psychology, 46A, 137-159.

Humphrey, G. K., \& KHAN, S. C. (1992). Recognising novel views of 3-D objects. Canadian Journal of Psychology, 46, 170-190.

HuMPhREY, G. K., \& LUPKER, S. J. (1993). Codes and operations in picture matching. Psychological Research, 55, 237-247.

Humphreys, G. W., \& RidDoch, M. J. (1984). Route to object constancy: Implications from neurological impairments of object constancy. Quarterly Journal of Experimental Psychology, 49A, 596-615.

Johnston, R. A., BarRy, C., \& Williams, C. (1996). Incomplete faces don't show the whole picture: Repetition priming from jumbled faced. Quarterly Journal of Experimental Psychology, 41A, 775-796.

JOLICOEUR, P. (1985). The time to name disoriented natural objects. Memory \& Cognition, 13, 289-303.

JOLICOEUR, P., \& MILLIKEN, B. (1989). Identification of disoriented objects: Effects of context of prior presentation. Journal of Experimental Psychology: Learning, Memory \& Cognition, 15, 200-210.

LAWSON, R., \& Humphreys, G. W. (1996). View-specificity in object processing: Evidence from picture matching. Journal of Experimental Psychology: Human Perception \& Performance, 22, 395-416. 
Lawson, R., \& Humphreys, G. W. (in press). The effects of view in depth on the identification of line drawings and silhouettes of familiar objects: Normality and pathology. Visual Cognition.

MARR, D. (1982). Vision. San Francisco: Freeman.

Palmer, S., Rosch, E., \& Chase, P. (1981). Canonical perspective and the perception of objects. In J. Long \& A. Baddeley (Eds.), Attention and performance $I X$ (pp. 135-151). Hillsdale, NJ: Erlbaum.

Rock, I., \& Di VITA, J. (1987). A case of viewer-centered object perception. Cognitive Psychology, 19, 280-293.

RoCk, I., Di VITA, J., \& BARBEITo, R. (1981). The effect on form perception of changing orientation in the third dimension. Journal of Experimental Psychology: Human Perception \& Performance, 7, 719-732.

SRINIVAS, K. (1993). Perceptual specificity in nonverbal priming. Journal of Experimental Psychology: Learning, Memory, \& Cognition, 19, 582-602.

SRINIVAS, K. (1995). Representation of rotated objects in explicit and implicit memory. Journal of Experimental Psychology: Learning, Memory, \& Cognition, 21, 1019-1036.
TARR, M. J., \& BülthofF, H. H. (1995). Is human object recognition better described by geon structural descriptions or by multiple views? Comment on Biederman and Gerhardstein (1993). Journal of Experimental Psychology: Human Perception \& Performance, 21, 1494-1505.

Tarr, M. J., Hayward, W. G., Gauthier, I., \& Williams, P. (1994 November). Geon recognition is viewpoint dependent. Paper presented at the 35th Annual Meeting of the Psychonomic Society, St. Louis.

TARR, M. J., \& PinKER, S. (1989). Mental rotation and orientation dependence in shape recognition. Cognitive Psychology, 21, 233-283.

WARREN, C., \& MORTON, J. (1982). The effects of priming on picture recognition. British Journal of Psychology, 73, 117-129.

WARRINGTON, E. K., \& TAYLOR, A. M. (1973). The contribution of the right parietal lobe to object recognition. Cortex, 9, 152-164.

WARRINGTON, E. K., \& TAYLOR, A. M. (1978). Two categorical stages of object recognition. Perception, 7, 695-705.

WHEELDON, L. R., \& MONSELL, S. (1992). The locus of repetition priming of spoken word production. Quarterly Journal of Experimental Psychology, 44A, 723-761.

APPENDIX A

The 36 Objects Presented in Experiment 1

\begin{tabular}{lll}
\hline banana & kangaroo & screwdriver \\
bone & key & shoe \\
camel & knife & spanner \\
can opener & leek & spectacles \\
car & loaf & spoon \\
clothes peg & paperclip & stapler \\
coat hanger & pen & telephone \\
comb & pencil & tennis racquet \\
corkscrew & razor & toothbrush \\
fork & ruler & torch \\
hammer & saw & train \\
iron & scissors & whisk \\
\hline
\end{tabular}

APPENDIX B

The 72 Objects Presented in Experiments 2 and 3

\begin{tabular}{llll}
\multicolumn{1}{c}{ Animals } & \multicolumn{1}{c}{ Machines } & \multicolumn{1}{c}{ Vehicles } & Household \\
\hline bird & binoculars & aeroplane & boot \\
camel & calculator & bicycle & cassette tape \\
cow & camera & bulldozer & catapult \\
crocodile & can opener & bus & clothes peg \\
deer & clock & cannon & pair com- \\
passes & & & \\
dinosaur & corkscrew & car & dustpan \\
dog & gun & caravan & hair clip \\
elephant & holepunch & cement mixer & ink jar \\
giraffe & iron & dinghy & jug \\
hippopotamus & kettle & forklift & mug \\
horse & lamp & helicopter & oil can \\
kangaroo & lighter & horsebox & paperclip \\
pig & radio & hovercraft & pint glass \\
rhinoceros & weighing scales & lorry & saucepan \\
sheep & stapler & steamroller & shoe \\
tortoise & telephone & tank & teapot \\
walrus & toaster & tractor & trophy \\
whale & whisk & train & wardrobe \\
\hline
\end{tabular}

(Manuscript received January 6, 1997;

revision accepted for publication August 5, 1997.) 